\title{
Noninvasive brain stimulation by radioelectric asymmetric conveyor in the treatment of agoraphobia: open-label, naturalistic study
}

This article was published in the following Dove Press journal:

Patient Preference and Adherence

17 November 201।

Number of times this article has been viewed

Piero Mannu

Salvatore Rinaldi

Vania Fontani

Alessandro Castagna

Matteo Lotti Margotti

Department of Neuro Psycho Physio Pathology, Rinaldi Fontani Institute, Florence, Italy
Correspondence: Salvatore Rinaldi Rinaldi Fontani Institute,

Viale Belfiore 43, 50I44 Florence, Italy

Tel +39055 290307

Fax +39055290399

Email srinaldi@irf.it
Background: Agoraphobia is considered to be the most serious complication of panic disorder. It involves progressive development of debilitating anxiety symptoms related to being in situations where one would be extremely embarrassed and could not be rescued in the case of a panic attack. This study aimed to investigate the efficacy of noninvasive brain stimulation using a radioelectric asymmetric conveyor (REAC) for agoraphobia.

Patients and methods: Twenty-three patients ( 3 males and 20 females) suffering from agoraphobia and without a history of panic disorder were evaluated by a psychiatrist using the Diagnostic and Statistical Manual of Mental Disorders, Fourth Edition, Text Revision, and the Agoraphobia Scale (AS). The patients were subjected to two 18-session cycles of noninvasive brain stimulation with the REAC, according to an established therapeutic protocol called neuropsycho-physical optimization.

Results: Analyzing the anxiety and avoidance parameters of the AS after the first and second cycles of REAC treatment revealed variation in levels of response to treatment, including weak (AS item 7), moderate (AS items 10 and 13), and good responses (AS items 1-6, 8, 9, 11, 12, and 14-20).

Conclusion: These results highlight the potential of the REAC to treat complex clinical situations such as agoraphobia, which is typically resistant to pharmacologic treatments. Furthermore, these data show the advantages of REAC treatment, even compared with modern cognitive behavioral therapy, including a relatively rapid and "stable" clinical response (just over 6 months) and economic cost.

Keywords: anxiety, avoidance, fear, REAC

\section{Introduction}

Agoraphobia is considered to be the most serious complication of panic disorder. According to the Diagnostic and Statistical Manual of Mental Disorders, Fourth Edition, Text Revision (DSM-IV-TR), ${ }^{1-3}$ agoraphobia is a progressive development of debilitating anxiety symptoms related to being in situations where one would be extremely embarrassed and could not be rescued in the case of a panic attack.

The typical constellation of agoraphobic symptoms emerges in specific circumstances ${ }^{4}$ such as being out of the house alone or in the midst of many unknown people, waiting in line, navigating a bridge or tunnel, or traveling by car, bus, plane, or train. Furthermore, other less common manifestations of agoraphobia such as the need to wear sunglasses, carry items such as a bottle of water or anti-anxiety medications, or being unable to wear a turtleneck, necktie, or even a ring have been described. ${ }^{5}$ Therefore, an agoraphobic person tends to avoid places and/or situations that may 
induce a panic attack, and, if the individual must be in these situations, they experience extreme discomfort and the conviction of an imminent panic attack. ${ }^{5}$ In many affected individuals, this develops into an uncontrollable need to use a "companion guide" - defined as a trusted person, usually a friend or relative - to cope with the more common acts of normal social life. Although agoraphobia is a complication/ consequence of panic disorder, the DSM-IV-TR also describes agoraphobia without a history of panic disorder. This condition is difficult to assess but it seems to affect between $0.6 \%$ and $6 \%$ of the general population, especially women. ${ }^{1,6,7}$ However, it is widely believed that agoraphobia is always preceded by panic attacks, which may be triggered by specific, well-demonstrated factors or may be subthreshold ${ }^{8}$ with an atypical manifestation. According to this conceptual approach, panic disorder always begins with recurrent, unexpected panic attacks, which occur in typical neurovegetative form due to activation of the locus coeruleus, ${ }^{9-11}$ less frequently, and bioelectrical desynchronization of the temporal lobes, causing depersonalization-derealization panic-related syndrome. In the next stage, the complex of anticipatory and intercritical anxiety arises, caused by persistent limbic activation. Finally, agoraphobia develops, supported by a progressive pattern of cortical processing, fear, and avoidance.

Pharmacologic treatment of panic disorder and anticipatory and intercritical anxiety with selective serotonin reuptake inhibitors and serotonin and norepinephrine reuptake inhibitors has excellent results. However, agoraphobia remains largely refractory to these approaches, and only sporadic and inconclusive data support the effectiveness of cognitive behavioral psychotherapy. ${ }^{12-17}$ Therefore, this study aimed to investigate the efficacy of noninvasive brain stimulation using a radioelectric asymmetric conveyor (REAC) for agoraphobia.

\section{Materials and methods \\ Patients}

Twenty-three patients ( 3 males, 20 females) participated in this study. Mean age of onset was $29.4 \pm 2.4$ years, mean age when diagnosis was made was $36.6 \pm 1.8$ years, and age range was 34-41 years. Patients were referred to our institute with a diagnosis of agoraphobia without a history of panic disorder. All patients were evaluated by a psychiatrist according to DSM-IV-TR criteria ${ }^{2,3,18}$ and all were assessed using the Agoraphobia Scale (AS). ${ }^{19}$

\section{The AS}

The $\mathrm{AS}^{19}$ is a self-administered questionnaire and consists of 20 items divided into two sections that describe common agoraphobic situations. Since anxiety can be present in absence of avoidance and (more rarely) vice versa, the first section of this psychometric instrument captures the anxiety parameters and is rated from 0 (no anxiety) to 4 (extreme anxiety). The second section captures the avoidance parameters and is rated from 0 (absent avoidance) to 2 (constant avoidance). The AS was administered in this study by a team of psychiatrists at baseline screening $(\mathrm{t} 0)$ and about 1 month after the end of the first ( $t 1)$ and second ( $t 2)$ cycles of noninvasive brain stimulation. The AS is easy for the patient to complete and takes about 10 minutes.

\section{The REAC device}

The REAC $^{20,21}$ is a medical biostimulation device based on innovative technology. The model used in this study (Convogliatore di Radianza Modulante; ASMED, Florence, Italy) is specific for noninvasive brain stimulation techniques.

Patients underwent noninvasive brain stimulation REAC treatment, according to the standardized protocol of neuro-psycho-physical-optimization (NPPO). The REAC-NPPO treatment protocol consisted of seven radio

Table I Agoraphobia Scale items

\begin{tabular}{|c|c|}
\hline Item & Description \\
\hline I & Being alone in your home \\
\hline 2 & $\begin{array}{l}\text { Shopping unaccompanied in small shops (eg, a grocery, } \\
\text { pharmacy, etc) }\end{array}$ \\
\hline 3 & Crossing a street in the city alone \\
\hline 4 & Being in a crowd unaccompanied \\
\hline 5 & Traveling on a bus unaccompanied, when it is crowded \\
\hline 6 & $\begin{array}{l}\text { Walking straight across large open spaces in the city } \\
\text { (eg, a square) }\end{array}$ \\
\hline 7 & Driving a car alone through a long tunnel \\
\hline 8 & Walking away from your home alone \\
\hline 9 & $\begin{array}{l}\text { Traveling by train or underground unaccompanied, when it is } \\
\text { crowded }\end{array}$ \\
\hline 10 & $\begin{array}{l}\text { Standing unaccompanied in a long queue in a post office, bank, } \\
\text { supermarket, etc }\end{array}$ \\
\hline $\mathrm{II}$ & $\begin{array}{l}\text { Sitting on a chair for a long time, when in the company of } \\
\text { other people }\end{array}$ \\
\hline 12 & Eating at a restaurant or café \\
\hline 13 & Sitting in the middle of a row at a cinema or theater \\
\hline 14 & $\begin{array}{l}\text { Shopping unaccompanied in a department store that is full } \\
\text { of people }\end{array}$ \\
\hline 15 & $\begin{array}{l}\text { Walking over a bridge when there are a lot of people and } \\
\text { traffic about }\end{array}$ \\
\hline 16 & Driving a car alone over a bridge \\
\hline 17 & Having a haircut at the hairdresser, unaccompanied \\
\hline 18 & $\begin{array}{l}\text { Shopping unaccompanied in a large supermarket, crowded } \\
\text { with people }\end{array}$ \\
\hline 19 & Walking in a crowded street unaccompanied \\
\hline 20 & Riding in an elevator unaccompanied \\
\hline
\end{tabular}


frequency bursts of 500 milliseconds each at a frequency of $10.5 \mathrm{GHz}$ and with a specific absorption rate of $7 \mu \mathrm{W} / \mathrm{kg}$, applied by touching the metallic tip of the REAC probe to the pavilion of the ear. REAC treatment has proven efficacy in ameliorating several stress-related disorders, ${ }^{22-26}$ as well as depression, ${ }^{26-28}$ anxiety, ${ }^{26,28}$ bipolar disorder, ${ }^{29}$ and some forms of dementia. ${ }^{30}$

The REAC treatment protocol for this study consisted of two 18-session cycles of brain stimulation applied to the ear. In every session, seven specific points of the pavilion of the ear were stimulated, and this noninvasive and painless procedure lasted about 3.5 seconds. The first REAC treatment cycle was separated from the following cycle by an interval of about 6 months.

\section{Statistical analysis}

Two statistical tests, the Wilcoxon signed-rank test and the Sign test, were used to compare the mean and standard deviation of all AS items for anxiety and for avoidance between pairs of timepoints ( $\mathrm{t} 1$ and $\mathrm{t} 0$; $\mathrm{t} 2$ and $\mathrm{t} 0$; $\mathrm{t} 2$ and $\mathrm{t} 1$ ). Variation in AS item scores was used to determine which items showed low, medium, and good responses to REAC treatment.

\section{Results}

At baseline ( $\mathrm{t} 0$ ), the average total AS score for all items (Table 1) for "anxiety" was $3.3 \pm 0.3$, corresponding to a "severe" clinical picture, while the average total score for all items relating to "avoidance" was $1.5 \pm 0.3$, indicating strong and very frequent avoidant behavior. Approximately 1 month after the end of the first cycle (t1) of REAC-NPPO therapy, the average total AS score of all the items for "anxiety" decreased slightly, to $2.8 \pm 1.6$, corresponding to a clinical picture pathologically less important than that observed at $\mathrm{t} 0$, but not significant from a statistical point of view, at least in general terms. In fact, the relative score for "anxiety" for some items such as 1, 20, and 3 were significantly reduced.

The same holds with regard to the average total AS score for all the items for "avoidance" reduced to $1.3 \pm 0.4$, although, also in this case, the abovementioned items were significantly decreased. Approximately 1 month after the end of the second cycle (t2) of REAC-NPPO therapy, the average total AS score for all the items for "anxiety" decreased significantly, to $2.4 \pm 0.4$, and the average total AS score for all the items for "avoidance" also decreased significantly,

Table 2 Agoraphobia Scale: anxiety

\begin{tabular}{|c|c|c|c|c|c|c|c|c|c|}
\hline \multirow[t]{3}{*}{ Item } & \multirow{2}{*}{\multicolumn{3}{|c|}{ Average change (\%) }} & \multicolumn{6}{|c|}{ Statistical test } \\
\hline & & & & \multicolumn{3}{|c|}{ Wilcoxon Z; Asymp Sig } & \multicolumn{3}{|c|}{ Sign test Exact Sig } \\
\hline & tI-t0 & t2-t0 & t2-tl & tl-to & t2-t0 & t2-tl & tl-to & t2-t0 & t2-tl \\
\hline \multicolumn{10}{|c|}{ Significant response to treatment } \\
\hline I & 64.10 & 74.36 & 28.57 & $-4.28 ; 0.000$ & $-4.33 ; 0.000$ & $-4.28 ; 0.000$ & 0.000 & 0.000 & 0.008 \\
\hline 2 & 22.37 & 72.37 & 64.41 & $-3.69 ; 0.000$ & $-4.33 ; 0.000$ & $-3.69 ; 0.000$ & 0.000 & 0.000 & 0.000 \\
\hline 3 & 66.67 & 74.36 & 23.08 & $-4.28 ; 0.000$ & $-4.33 ; 0.000$ & $-4.28 ; 0.034$ & 0.000 & 0.000 & 0.063 \\
\hline 4 & 22.37 & 72.37 & 64.41 & $-3.37 ; 0.001$ & $-4.33 ; 0.000$ & $-3.37 ; 0.000$ & 0.001 & 0.000 & 0.000 \\
\hline 5 & 22.37 & 73.68 & 66.10 & $-3.49 ; 0.000$ & $-4.33 ; 0.000$ & -3.490 .000 & 0.000 & 0.000 & 0.000 \\
\hline 6 & 21.33 & 72.00 & 64.41 & $-2.96 ; 0.003$ & $-4.29 ; 0.000$ & $-2.96 ; 0.000$ & 0.003 & 0.000 & 0.000 \\
\hline 8 & 21.33 & 72.00 & 64.41 & $-3.02 ; 0.000$ & $-4.32 ; 0.000$ & $-4.32 ; 0.000$ & 0.001 & 0.000 & 0.000 \\
\hline 9 & 22.37 & 73.68 & 66.10 & $-3.49 ; 0.000$ & $-4.31 ; 0.000$ & $-4.39 ; 0.000$ & 0.000 & 0.000 & 0.000 \\
\hline II & 22.37 & 73.68 & 66.10 & $-3.49 ; 0.000$ & $-4.33 ; 0.000$ & $-4.34 ; 0.000$ & 0.000 & 0.000 & 0.000 \\
\hline 12 & 22.37 & 72.37 & 64.41 & $-3.69 ; 0.000$ & $-4.36 ; 0.000$ & $-4.32 ; 0.000$ & 0.000 & 0.000 & 0.000 \\
\hline 14 & 23.38 & 72.73 & 64.41 & $-3.22 ; 0.001$ & $-4.31 ; 0.000$ & $-4.32 ; 0.000$ & 0.001 & 0.000 & 0.000 \\
\hline 15 & 22.37 & 73.68 & 66.10 & $-3.49 ; 0.000$ & $-4.33 ; 0.000$ & $-4.34 ; 0.000$ & 0.000 & 0.000 & 0.000 \\
\hline 16 & 25.32 & 73.42 & 64.41 & $-3.54 ; 0.000$ & $-4.33 ; 0.000$ & $-4.32 ; 0.000$ & 0.000 & 0.000 & 0.000 \\
\hline 17 & 22.37 & 73.68 & 66.10 & $-3.54 ; 0.000$ & $-4.27 ; 0.000$ & $-4.39 ; 0.000$ & 0.000 & 0.000 & 0.000 \\
\hline 18 & 22.37 & 72.37 & 64.41 & $-3.22 ; 0.00 \mathrm{I}$ & $-4.27 ; 0.000$ & $-4.32 ; 0.000$ & 0.001 & 0.000 & 0.000 \\
\hline 19 & 36.84 & 73.68 & 58.33 & $-4.32 ; 0.000$ & $-4.33 ; 0.000$ & $-4.46 ; 0.000$ & 0.000 & 0.000 & 0.000 \\
\hline 20 & 55.26 & 72.37 & 38.24 & $-4.17 ; 0.000$ & $-4.27 ; 0.000$ & $-3.36 ; 0.001$ & 0.000 & 0.000 & 0.000 \\
\hline \multicolumn{10}{|c|}{ Moderate response to treatment } \\
\hline 10 & 22.37 & 72.37 & 64.41 & $-2.76 ; 0.006$ & $-3.36 ; 0.001$ & $-2.00 ; 0.046$ & 0.004 & 0.000 & 0.125 \\
\hline 13 & 66.67 & 74.36 & 23.08 & $-3.22 ; 0.001$ & $-3.46 ; 0.001$ & $-2.24 ; 0.025$ & 0.001 & 0.000 & 0.063 \\
\hline \multicolumn{10}{|c|}{ Low response to treatment } \\
\hline 7 & 1.28 & 2.56 & 1.30 & $-1.00 ; 0.317$ & $-1.4 \mid ; 0.157$ & $-1.00 ; 0.317$ & $\mathrm{NR}^{*}$ & 0.500 & NR* \\
\hline
\end{tabular}

Note: *Sign test algorithm gave no response value in this instable case.

Abbreviations: Asymp Sig, asymptotic significance (two-tailed); Exact Sig, exact significance (two-tailed); NR, no response. 
to $0.9 \pm 0.2$. Furthermore, with respect to t0, some items showed an even greater statistical significance, especially for "avoidance": specifically, items 1, 20, and 3.

Globally, in the comparison between $\mathrm{t} 2$ and $\mathrm{t} 0$, itemby-item analysis showed a weak response to treatment for anxiety (Table 2) and avoidance (Table 3) on item 7. A moderate response was observed for items 10 and 13 . A good, statistically significant response was observed for items 1-6, 9, 11, 12, and 14-20.

\section{Discussion}

The current results highlight the potential of REAC brain stimulation for the treatment of complex and chronic clinical conditions such as agoraphobia that are typically resistant to current pharmacologic treatments. The relatively rapid therapeutic effect, appearing in just a few months, highlights important time and economic advantages, even in comparison with novel cognitive behavioral treatment strategies. In general terms, the anxiety component of this clinical condition improved from very severe and pervasive to limited severity, and the avoidance component improved from disabling to subthreshold and manageable picture. Therefore, on the basis of clinical observation and the reductions in total AS scores, the response to REAC-NPPO therapy appears to be very favorable. It is interesting to note that, compared with previous studies published on bipolar disorder, ${ }^{29}$ panic disorder, ${ }^{27}$ generalized anxiety disorder, ${ }^{25,26,28}$ Alzheimer's disease, ${ }^{30}$ and various stressrelated disorders, ${ }^{22-26}$ the response of agoraphobia to REACNPPO therapy was slower and less robust, as significant improvement on anxiety and avoidance was not present at the first timepoint (t1). One possible explanation for this could be that agoraphobia may be a secondary complication of the primary disorder (ie, panic disorder) and would therefore be less affected by treatment, similar to the effects of treatment on alcohol dependence in an individual with social anxiety disorder. Another explanation could be that the long interval of time between the onset and diagnosis of agoraphobia delays the first therapeutic attempt. This critical delay may favor establishment of neuroanatomical circuitry that supports agoraphobic thoughts and related avoidant behaviors. Finally, agoraphobia without symptoms of panic

Table 3 Agoraphobia Scale: avoidance

\begin{tabular}{|c|c|c|c|c|c|c|c|c|c|}
\hline \multirow[t]{3}{*}{ Item } & \multirow{2}{*}{\multicolumn{3}{|c|}{ Average change (\%) }} & \multicolumn{6}{|c|}{ Statistical test } \\
\hline & & & & \multicolumn{3}{|c|}{ Wilcoxon Z; Asymp Sig } & \multicolumn{3}{|c|}{ Sign test Exact Sig } \\
\hline & tI-to & t2-t0 & t2-tl & tI-to & t2-t0 & t2-tl & tI-to & t2-t0 & t2-tl \\
\hline \multicolumn{10}{|c|}{ Significant response to treatment } \\
\hline I & 64.10 & 74.36 & 28.57 & $-4.28 ; 0.000$ & $-4.33 ; 0.000$ & $-4.28 ; 0.000$ & 0.000 & 0.000 & 0.008 \\
\hline 2 & 22.37 & 72.37 & 64.41 & $-3.69 ; 0.000$ & $-4.33 ; 0.000$ & $-3.69 ; 0.000$ & 0.000 & 0.000 & 0.000 \\
\hline 3 & 66.67 & 74.36 & 23.08 & $-4.28 ; 0.000$ & $-4.33 ; 0.000$ & $-4.28 ; 0.034$ & 0.000 & 0.000 & 0.063 \\
\hline 4 & 22.37 & 72.37 & 64.41 & $-3.37 ; 0.001$ & $-4.33 ; 0.000$ & $-3.37 ; 0.000$ & 0.001 & 0.000 & 0.000 \\
\hline 5 & 22.37 & 73.68 & 66.10 & $-3.49 ; 0.000$ & $-4.33 ; 0.000$ & -3.490 .000 & 0.000 & 0.000 & 0.000 \\
\hline 6 & 21.33 & 72.00 & 64.41 & $-2.96 ; 0.003$ & $-4.29 ; 0.000$ & $-2.96 ; 0.000$ & 0.003 & 0.000 & 0.000 \\
\hline 8 & 21.33 & 72.00 & 64.41 & $-3.02 ; 0.000$ & $-4.32 ; 0.000$ & $-4.32 ; 0.000$ & 0.001 & 0.000 & 0.000 \\
\hline 9 & 22.37 & 73.68 & 66.10 & $-3.49 ; 0.000$ & $-4.31 ; 0.000$ & $-4.39 ; 0.000$ & 0.000 & 0.000 & 0.000 \\
\hline II & 22.37 & 73.68 & 66.10 & $-3.49 ; 0.000$ & $-4.33 ; 0.000$ & $-4.34 ; 0.000$ & 0.000 & 0.000 & 0.000 \\
\hline 12 & 22.37 & 72.37 & $64.4 I$ & $-3.69 ; 0.000$ & $-4.36 ; 0.000$ & $-4.32 ; 0.000$ & 0.000 & 0.000 & 0.000 \\
\hline 14 & 23.38 & 72.73 & 64.41 & $-3.22 ; 0.001$ & $-4.31 ; 0.000$ & $-4.32 ; 0.000$ & 0.001 & 0.000 & 0.000 \\
\hline 15 & 22.37 & 73.68 & 66.10 & $-3.49 ; 0.000$ & $-4.33 ; 0.000$ & $-4.34 ; 0.000$ & 0.000 & 0.000 & 0.000 \\
\hline 16 & 25.32 & 73.42 & $64.4 I$ & $-3.54 ; 0.000$ & $-4.33 ; 0.000$ & $-4.32 ; 0.000$ & 0.000 & 0.000 & 0.000 \\
\hline 17 & 22.37 & 73.68 & 66.10 & $-3.54 ; 0.000$ & $-4.27 ; 0.000$ & $-4.39 ; 0.000$ & 0.000 & 0.000 & 0.000 \\
\hline 18 & 22.37 & 72.37 & 64.41 & $-3.22 ; 0.001$ & $-4.27 ; 0.000$ & $-4.32 ; 0.000$ & 0.001 & 0.000 & 0.000 \\
\hline 19 & 36.84 & 73.68 & 58.33 & $-4.32 ; 0.000$ & $-4.33 ; 0.000$ & $-4.46 ; 0.000$ & 0.000 & 0.000 & 0.000 \\
\hline 20 & 55.26 & 72.37 & 38.24 & $-4.17 ; 0.000$ & $-4.27 ; 0.000$ & $-3.36 ; 0.001$ & 0.000 & 0.000 & 0.000 \\
\hline \multicolumn{10}{|c|}{ Moderate response to treatment } \\
\hline 10 & 22.37 & 72.37 & $64.4 I$ & $-2.76 ; 0.006$ & $-3.36 ; 0.00 \mathrm{I}$ & $-2.00 ; 0.046$ & 0.004 & 0.000 & 0.125 \\
\hline 13 & 66.67 & 74.36 & 23.08 & $-3.22 ; 0.001$ & $-3.46 ; 0.001$ & $-2.24 ; 0.025$ & 0.001 & 0.000 & 0.063 \\
\hline \multicolumn{10}{|c|}{ Low response to treatment } \\
\hline 7 & 1.28 & 2.56 & 1.30 & $-1.00 ; 0.317$ & $-1.41 ; 0.157$ & $-1.00 ; 0.317$ & NR* & 0.500 & $\mathrm{NR}^{*}$ \\
\hline
\end{tabular}

Note: *Sign test algorithm gave no response value in this instable case.

Abbreviations: Asymp Sig, asymptotic significance (two-tailed); Exact Sig, exact significance (two-tailed); NR, no response. 
disorder does not usually appear suddenly and severely; rather, it subtly insinuates itself, gradually influencing thoughts and attitudes and preventing an individual from mobilizing appropriate defense strategies. However, as previously noted, some AS items had already improved after the first cycle of REAC-NPPO therapy. This suggests that qualitative analysis of clinical data is justified to determine the health status of the individual. Using this approach, the majority of the patients felt globally better after the first cycle of REAC-NPPO therapy, and this effect was close to statistical significance. After the second cycle of treatment, the improvement from baseline was more evident. In fact, one of the most interesting features of REAC-NPPO is the enhancement in efficacy observed across repeated cycles. In addition and according to our experience about this peculiar kind of brain stimulation, it is important to discontinue therapy for a period of 4-6 months. This interval may allow a sort of "deep reorganization" (optimization) of brain and/or mental functions, as with agoraphobia, where the tendency to avoid harm overcomes other survival parameters, such as novelty seeking and reward dependence.

\section{Conclusion}

Although this was an open-label, naturalistic study conducted on a small number of patients, it was the first study to explore the potential of brain stimulation in a clinical disorder such as agoraphobia, a disorder with no clear organic framework. The refractory nature of agoraphobia to current treatments, combined with the great suffering and progressive functional impairment of patients, necessitates development of new therapeutic strategies to promote social rehabilitation. The unique, noninvasive brain stimulation achieved by REAC appears very promising because of its high tolerability and good safety profile.

Clearly, considering the obvious limitations, more rigorous studies should investigate the effects of REAC in double-blind, placebo-controlled designs in a larger sample to determine the potential of this approach for agoraphobia and other, similar conditions. Furthermore, since agoraphobia is a chronic condition, longer observation periods are needed; this may also help to reduce any possible and nonspecific positive role that can be produced through the enthusiasm of being subjected to an innovative treatment technology.

\section{Disclosure}

Salvatore Rinaldi and Vania Fontani are the inventors of the REAC.

\section{References}

1. Grant BF, Hasin DS, Stinson FS, et al. The epidemiology of DSM-IV panic disorder and agoraphobia in the United States: results from the National Epidemiologic Survey on Alcohol and Related Conditions. J Clin Psychiatry. 2006;67(3):363-374.

2. Manfredi de Poderoso C, Linetzky L. Panic disorders and agoraphobia: Freudian concepts and DSM IV. Vertex. 2003;14(51): 16-21. Spanish.

3. Schmidt NB, Salas D, Bernert R, Schatschneider C. Diagnosing agoraphobia in the context of panic disorder: examining the effect of DSM-IV criteria on diagnostic decision-making. Behav Res Ther. 2005; 43(9):1219-1229.

4. Berle D, Starcevic V, Milicevic D, Hannan A, Moses K. Do symptom interpretations mediate the relationship between panic attack symptoms and agoraphobic avoidance? Behav Cogn Psychother. 2010;38(3): 275-289.

5. Cassano GB, Michelini S, Shear MK, Coli E, Maser JD, Frank E. The panic-agoraphobic spectrum: a descriptive approach to the assessment and treatment of subtle symptoms. Am J Psychiatry. 1997;154(Suppl 6): 27-38.

6. Faravelli C, Cosci F, Rotella F, Faravelli L, Catena Dell'osso M Agoraphobia between panic and phobias: clinical epidemiology from the Sesto Fiorentino Study. Compr Psychiatry. 2008;49(3):283-287.

7. Goodwin RD, Faravelli C, Rosi S, et al. The epidemiology of panic disorder and agoraphobia in Europe. Eur Neuropsychopharmacol. 2005; 15(4):435-443.

8. Rubino IA, Romeo D, Siracusano A. Styles of adaptation in panic disorder with and without agoraphobia. Percept Mot Skills. 2003; 97(3 Pt 2):1223-1230.

9. Priolo E, Libri V, Lopilato R, David E, Nappi G, Nisticò G. Panic-like attack induced by microinfusion into the locus coeruleus of antagonists and inverse agonists at GABAA-receptors in rodents. Funct Neurol. 1991;6(4):393-403.

10. Hellsten KS, Sinkkonen ST, Hyde TM, et al. Human locus coeruleus neurons express the GABA(A) receptor gamma2 subunit gene and produce benzodiazepine binding. Neurosci Lett. 2010;477(2):77-81.

11. Gargaglioni LH, Hartzler LK, Putnam RW. The locus coeruleus and central chemosensitivity. Respir Physiol Neurobiol. 2010;173(3): 264-273.

12. Galassi F, Quercioli S, Charismas D, Niccolai V, Barciulli E. Cognitivebehavioral group treatment for panic disorder with agoraphobia. J Clin Psychol. 2007;63(4):409-416.

13. Gloster AT, Wittchen HU, Einsle F, et al. Psychological treatment for panic disorder with agoraphobia: a randomized controlled trial to examine the role of therapist-guided exposure in situ in CBT. J Consult Clin Psychol. 2011;79(3):406-420.

14. Hoffart A, Hedley LM, Thornes K, Larsen SM, Friis S. Therapists' emotional reactions to patients as a mediator in cognitive behavioural treatment of panic disorder with agoraphobia. Cogn Behav Ther. 2006; 35(3):174-182.

15. Pitti C, Peñate $\mathrm{W}$, de la Fuente J, et al. Agoraphobia: combined treatment and virtual reality; preliminary results. Actas Esp Psiquiatr. 2008;36(2):94-101. Spanish.

16. Roberge P, Marchand A, Reinharz D, Savard P. Cognitive-behavioral treatment for panic disorder with agoraphobia: a randomized, controlled trial and cost-effectiveness analysis. Behav Modif. 2008;32(3): 333-351.

17. Sánchez-Meca J, Rosa-Alcázar AI, Marín-Martínez F, Gómez-Conesa A. Psychological treatment of panic disorder with or without agoraphobia: a meta-analysis. Clin Psychol Rev. 2010;30(1):37-50.

18. Goisman RM, Warshaw MG, Steketee GS, et al. DSM-IV and the disappearance of agoraphobia without a history of panic disorder: new data on a controversial diagnosis. Am J Psychiatry. 1995;152(10): $1438-1443$.

19. Ost LG. The Agoraphobia Scale: an evaluation of its reliability and validity. Behav Res Ther. 1990;28(4):323-329. 
20. Rinaldi S, Fontani V, inventor; Rinaldi S, Fontani V, assignee. Radioelectric asymmetric conveyer for therapeutic use. United States patent EP1301241 (B1). October 11, 2006.

21. Rinaldi S, Fontani V, inventor; Rinaldi S, Fontani V, assignee. Radioelectric csymmetric conveyer for therapeutic use. United States patent 73338592001. 2001.

22. Collodel G, Moretti E, Fontani V, et al. Effect of emotional stress on sperm quality. Indian J Med Res. 2008;128(3):254-261.

23. Rinaldi S, Fontani V, Aravagli L, Mannu P. Psychometric evaluation of a radio electric auricular treatment for stress related disorders: a double-blinded, placebo-controlled controlled pilot study. Health Qual Life Outcomes. 2010;8(1):31.

24. Rinaldi S, Fontani V, Aravagli L, et al. Stress-related psycho-physiological disorders: randomized single blind placebo controlled naturalistic study of psychometric evaluation using a radio electric asymmetric treatment. Health Qual Life Outcomes. 2011;9(1):54.

25. Rinaldi S, Fontani V, Aravagli L, Margotti ML. Psychological and symptomatic stress-related disorders with radio-electric treatment: psychometric evaluation. Stress Health. 2010;26(5):350-358.
26. Rinaldi S, Fontani V, Moretti E, et al. A new approach on stressrelated depression and anxiety: Neuro-Psycho-Physical-Optimization with Radio Electric Asymmetric-Conveyer. Indian J Med Res. 2010; 132:189-194.

27. Mannu P, Rinaldi S, Fontani V, Castagna A, Margotti ML. Radio electric treatment vs Es-Citalopram in the treatment of panic disorders associated with major depression: an open-label, naturalistic study. Acupunct Electrother Res. 2009;34(3-4):135-149.

28. Olivieri EB, Vecchiato C, Ignaccolo N, et al. Radioelectric brain stimulation in the treatment of generalized anxiety disorder with comorbid major depression in a psychiatric hospital: a pilot study. Neuropsychiatr Dis Treat. 2011;7:449-455.

29. Mannu P, Rinaldi S, Fontani V, Castagna A. Long-term treatment of bipolar disorder with a radioelectric asymmetric conveyor. Neuropsychiatr Dis Treat. 2011;7:373-379.

30. Mannu P, Rinaldi S, Fontani V, Castagna A. Radio electric asymmetric brain stimulation in the treatment of behavioral and psychiatric symptoms in Alzheimer disease. Clin Interv Aging. 2011;6:207-211.
Patient Preference and Adherence

\section{Publish your work in this journal}

Patient Preference and Adherence is an international, peer-reviewed, open access journal focusing on the growing importance of patient preference and adherence throughout the therapeutic continuum. Patient satisfaction, acceptability, quality of life, compliance, persistence and their role in developing new therapeutic modalities and compounds to

\section{Dovepress}

optimize clinical outcomes for existing disease states are major areas of interest. This journal has been accepted for indexing on PubMed Central. The manuscript management system is completely online and includes a very quick and fair peer-review system. Visit http://www.dovepress.com/ testimonials.php to read real quotes from published authors. 